\title{
Experimental and Numerical Failure Analysis of Adhesive Composite Joints
}

\author{
Farhad Asgari Mehrabadi \\ Department of Mechanical Engineering, Islamic Azad University, Arak Branch, Arak 567-38135, Iran \\ Correspondence should be addressed to Farhad Asgari Mehrabadi, f.asgari86@yahoo.com
}

Received 20 October 2011; Revised 8 January 2012; Accepted 23 January 2012

Academic Editor: R. Ganguli

Copyright ( $) 2012$ Farhad Asgari Mehrabadi. This is an open access article distributed under the Creative Commons Attribution License, which permits unrestricted use, distribution, and reproduction in any medium, provided the original work is properly cited.

In the first section of this work, a suitable data reduction scheme is developed to measure the adhesive joints strain energy release rate under pure mode-I loading, and in the second section, three types of adhesive hybrid lap-joints, that is, Aluminum-GFRP (Glass Fiber Reinforced Plastic), GFRP-GFRP, and Steel-GFRP were employed in the determination of adhesive hybrid joints strengths and failures that occur at these assemblies under tension loading. To achieve the aims, Double Cantilever Beam (DCB) was used to evaluate the fracture state under the mode-I loading (opening mode) and also hybrid lap-joint was employed to investigate the failure load and strength of bonded joints. The finite-element study was carried out to understand the stress intensity factors in DCB test to account fracture toughness using J-integral method as a useful tool for predicting crack failures. In the case of hybrid lap-joint tests, a numerical modeling was also performed to determine the adhesive stress distribution and stress concentrations in the side of lap-joint. Results are discussed in terms of their relationship with adhesively bonded joints and thus can be used to develop appropriate approaches aimed at using adhesive bonding and extending the lives of adhesively bonded repairs for aerospace structures.

\section{Introduction}

In recent years, adhesively bonded joints are used extensively in various industrial and technological applications including space technology, microelectronic packaging, as well as aerospace and automobile industries. These joints are being increasingly employed due to their interesting characteristics. Adhesive joints have good behavior under fatigue loads, allow the joining of different materials, and result in less stress concentrations compared to alternative joining techniques. In order to increase the confidence of designers, it is necessary to accurately predict their strengths. Adhesively bonded joints and bonded repairs of cracked metallic structures have been continuously receiving attention from the aerospace industry to enhance fatigue resistance and to restore the stiffness and strength of damaged/cracked structures. Therefore, there is a need for reliable models to predict the performance and durability of adhesively bonded assemblies.
Fracture characterization of bonded joints under pure mode-I has been extensively studied by several authors. Double Cantilever Beam (DCB) test is the most widely used method for measuring mode-I fracture toughness [1-5]. Various attempts have been made to characterize fracture toughness under mode-II and mixed-mode loading conditions in adhesively bonded joints [6-11]. Recently, cohesive zone models (CZMs) have been used to simulate damage onset and growth in order to predict the fracture behavior of bonded joints accurately $[12,13]$. In numerical approaches, Virtual Crack Closure Technique (VCCT) was used to calculate Strain Energy Release Rate (SERR) in adhesive bonding joint $[14,15]$. However, the mode-I, loading condition has particular importance for adhesive joints. In the case of strength of adhesive joint, extensive work has been done on the testing and modeling of single lap-joints under tension $[16,17]$. Several works can be found in the literature presenting the best solutions to improve the bond strength of different materials [18-21]. 
The authors in [22] studied Aluminum/mild steel adherends subjected to tensile shear loading. The lap-joint has been used to study metal joints, composite joints, and metal-to-composite joints and has also been used to look at fracture in composites that are representative of loading in real aerospace structures [23-29]. The overlap length for an ideal joint depends on the adhesive as well as the adherend materials [30].

The first part of this study focuses on fracture behavior of adhesive-bonded joints under pure opening condition employing DCB specimens. Three methods were applied in the experimental tests and their validity was confirmed through a numerical approach using J-integral method in order to account the fracture toughness in the adhesive joint.

In the second section of this study, the hybrid lap-joint specimen was employed to evaluate the strength of adhesive hybrid lap-joints under tension condition. The behavior of the joints was examined with changing various parameters such as overlap length and loading speed. A numerical modeling was performed by finite-element analysis to determine the adhesive stress distribution and stress concentrations in the lap-joint side.

\section{Data Reduction to Obtain Fracture Toughness}

The classical reduction schemes in the determination of the critical fracture energy in pure mode-I $\left(G_{I C}\right)$ are usually based on compliance calibration or the beam theory. The CCM is based on the Irwin-Kies equation [31]:

$$
G_{I C}=\frac{P^{2}}{2 B} \frac{d C}{d a},
$$

where $P$ represents the load, $B$ is the specimen width, and $C=\delta / P$ shows the compliance. The compliance values were used to fit $\log C$ versus $\log a$ curve, leading to

$$
G_{I C}=\frac{n P \delta}{2 B a},
$$

where $n$ is the slop of $\log C$ versus $\log a$ curve. Beam theories were also used to measure $G_{I C}$. Based on elementary beam theory, the DBT gives

$$
G_{I C}=\frac{12 P^{2} a^{2}}{B^{2} h^{3} E_{1}}
$$

where $h$ represents the height of each specimen arm and $E_{1}$ is Young's modulus of the adherends in the longitudinal direction. Using the CBM, $G_{I C}$ is obtained using

$$
G_{I C}=\frac{3 P \delta}{2 B(a+|\Delta|)},
$$

where $|\Delta|$ is a crack length correction for crack tip rotation and deflection. Using the beam theory, the relationship between compliance and crack length can be expressed as

$$
C=\frac{8(a+|\Delta|)^{3}}{E_{1} B h^{3}} \text {. }
$$

Thus,

$$
C^{1 / 3}=\frac{2}{h\left(E_{1} B\right)^{1 / 3}}(a+|\Delta|),
$$

which allows determining $|\Delta|$ from a linear regression of $C^{1 / 3}$ versus $a$ data.

\section{Classification of Failure Modes in Adhesive Joints}

According to the ASTM standard D5573-99 [32], there are seven classes of failure modes in adhesive joints that the test specimens (hybrid lap joints) will be classified based on the failure types described in the said standard. Failure modes are as follows.

(1) Adhesive failure (AF) (sometimes referred to as interfacial failure): separation appears to be at the adhesive-adherend interface.

(2) Cohesive failure (CF): separation is within the adhesive.

(3) Thin-layer cohesive failure (TLCF) (sometimes referred to as inter-phase failure): failure similar to cohesive failure, except that the failure is very close to the adhesive-adherend interface, characterized by a light dusting of adhesive on one adherend surface and a thick layer of adhesive left of the other.

(4) Fiber-tear failure (FTF): failure occurring exclusively within the fiber-reinforced plastic (FRP) matrix, characterized by the appearance of reinforcing fibers on both ruptured surfaces.

(5) Light-fiber-tear failure (LFTF): failure occurring within the FRP adherend, near the surface, characterized by a thin layer of the FRP resin matrix visible on the adhesive, with few or no glass fibers transferred from the adherend to the adhesive.

(6) Stock-break failure: this occurs when the separation is within the adherend but outside the bonded region.

(7) Mixed failure: a mixture of different classes.

\section{Sample Preparation and Testing}

4.1. DCB. DCB Samples were prepared with seven different crack lengths as $a_{\circ}=30,40,50,60,70,80,90 \mathrm{~mm}$ by GFRP adherends.

The geometry of the DCB specimens is presented in Figure 1 where $L=120 \mathrm{~mm}, h=5.2 \mathrm{~mm}, B=22 \mathrm{~mm}$, and $t=0.4 \mathrm{~mm}$. The GFRP adherends were made of composite laminates with twelve laminas and designated as $\left[0 / 90^{\circ}\right]_{12}$. Each lamina was made of E-glass woven cloth (AF 201, Colan Co., Australia) and epoxy resin (ML-506, Mokarrar Co., Ltd., Iran). The fiber volume fraction, $V_{\mathrm{f}}$, in the GFRP adherends was 50 percent. GFRP has been produced as a plate and then cut into required dimensions using the water jet. To fabricate the DCB samples, a constant adhesive thickness $(0.4 \mathrm{~mm})$ was guaranteed by placing the calibrated steel bars 


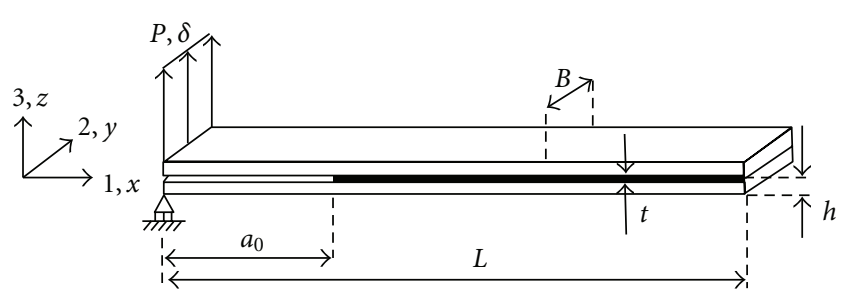

FIgURE 1: Schematic representation of the DCB test.

$(0.40 \pm 0.01 \mathrm{~mm})$ between the adherends and a non-adhering film (Teflon film with $0.076 \mathrm{~mm}$ thickness) during the curing process of the adhesive, thereafter, it was inserted into the interface of the adhesive layer in order to produce the starter crack. About three DCB specimens were tested with each crack length. The fracture tests were conducted by controlling the constant displacement rate of $1 \mathrm{~mm} / \mathrm{min}$ for DCB's in opening mode.

4.2. Lap-Joint. Three types of joints have been created to test hybrid lap-joint strength as follows:

Type I: Aluminum alloy-GFRP.

Type II: GFRP-GFRP.

Type III: Steel-GFRP.

The dimensions of hybrid lap-joints are based on the ASTM D 5868-01 standard. Figure 2 shows the geometry and dimensions of the test specimens. To make lap-joints, the calibrated steel plates were left at the room temperature during the bonding process of the adherends to ensure a constant adhesive thickness $(0.75 \mathrm{~mm})$. To investigate the influence of overlap length on the failure load and strength of bonded lap-joints, three different overlap length values were chosen: 15, 25.4, and $35 \mathrm{~mm}$ and also to find out the adhesive hybrid lap-joint assemblies sensitivity to the loading speed, three different loading speeds were chosen: $v=0.1,1.27$, and $10 \mathrm{~mm} / \mathrm{min}$ and at least three samples have been tested in each state.

The epoxy adhesive (Araldite, AD-314, Mokarrar Co. Iran) as a two-component toughened epoxy adhesive with desirable properties such as mechanical stability up to thicknesses of about $10 \mathrm{~mm}$ and also good bonding to composite materials and metals was employed in the bonding process. The properties of the adhesive taken from the manufacturer data sheets are given in Table 1. The adhesive was processed according to the manufacturer's specification. All the DCB and hybrid lap specimens were polished with 100\# mesh sandpaper and cleaned with acetone to increase its adhesion and to avoid adhesive failures.

All the DCB and lap joint specimens were tested with a universal testing machine (Galdabini, Sun 20) at room temperature. Figure 3(a) shows the DCB specimen under the mode-I loading and Figure 3(b) presents the experimental setup of hybrid lap test.

\section{Experimental Results}

5.1. The Mode I Fracture Toughness (DCB Test). For modeI loading conditions, at least three specimens were tested for each crack length and the average values of critical loads were obtained as it is shown in Table 2. Typically, the fracture test method requires obtaining three critical strain energy release rate values [35].

(1) $G_{C}$ (NL)-corresponds to the point where load versus Displacement curve of the test becomes nonlinear.

(2) $G_{C}(5 \% / \max )$ - corresponds to the point where a line $5 \%$ offset of the slope intersect the load displacement curve or the maximum load point, whichever occurs first.

(3) $G_{C}$ (VIS) — corresponds to the point where the actual crack initiation is visually observed by the testing personnel.

It is important to stress that only the maximum load point is proposed as the critical load at failure (initiation of crack growth) in this investigation. The average values of critical fracture loads were used to determine the critical strain energy values. It can be seen that the critical load at failure decreases with the increase of crack length. It should be mentioned that no plastic deformation observed in adherends after unloading and all the tested samples showed essentially a linear elastic behavior in failure. The critical fracture energy in the mode-I was evaluated using the three methods presented in Section 2. Figure 4 shows the experimental $R$-curve (Resistance curve) obtained for tested specimens through all the mentioned methods. As it is shown in Figure 4, the CCM and CBM present a slight difference compared to the DBT in different crack lengths. The calculated strain energy release rates, $G_{I C}$ values, are indications of bond durability because they quantitatively show how much energy should be put into the specimen to create the fracture. A two-polynomial curve was fitted on values obtained by the CBM. It shows the slope of $R$-curve increases in smaller crack lengths and gradually approaches into constant values. This is also true in the DBT and CCM.

The mean value of critical fracture energy obtained by DBT, CBM, and CCM is shown in Table 3.

A typical picture of crack path kinking for the mode-I load case is shown in Figure 5(a). The image of crack kinking was recorded during the DCB testing, using a 16 -MPixel digital camera. This case corresponds to the extreme case of nominal pure mode-I. Here, the most important observation is the persistence of crack kinking in all the specimens. Under this load case, the embedded crack initiated upwards into the adhesive layer and penetrated into it quickly. It is observed that the failure approaches to a separate adhesive layer and adherend, so the crack turned into upper adherend with kinking angle about $60^{\circ}$.

This issue has been investigated by [36] and it was observed that the turning angle increases as the mode-I grows towards the mode mixity (I+II) and mode-II (shearing mode). Figure 5(b) shows the failure surfaces for the DCB 


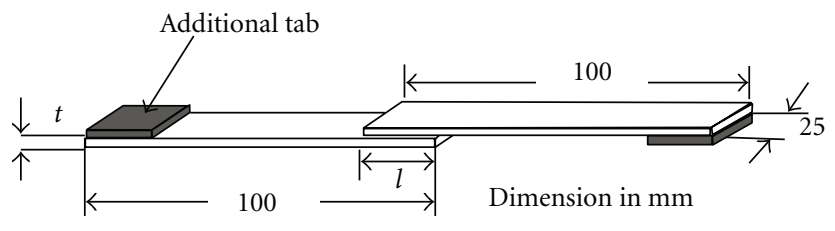

(a)

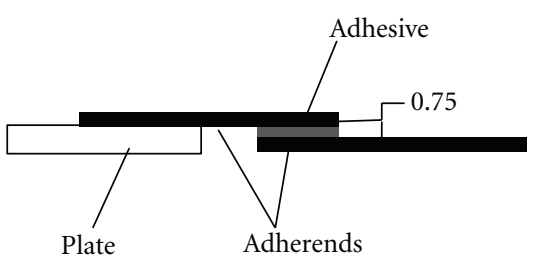

(b)

Figure 2: Dimensions of adherends and adhesive layer of lap-joints.

TABLE 1: Material properties of adherends and adhesive [33, 34].

\begin{tabular}{lcccc}
\hline & GFRP & Aluminum alloy & Steel (stainless) & Adhesive araldite AD-314 \\
\hline$E_{x}(\mathrm{GPa})$ & 20 & 71.7 & 190 & 2.25 \\
$E_{y}(\mathrm{GPa})$ & 20 & - & - & - \\
$G_{x y}(\mathrm{GPa})$ & 2.8 & - & - & -29 \\
$v_{x y}$ & .13 & .333 & .3 \\
\hline
\end{tabular}

sample after debonding. As it can be seen, under quasistatic loading, the crack path was mostly cohesive in which 10-20\% of the failure surface is being interfacial failure. As expected, after the crack initiation, the failure surface propagated stably and became unstable when the adhesive damage zone had fully developed.

It can be seen from the $R$-curve that the length of stable crack grows during the rising part of the $R$-curve in the DCB tests and the length of unstable crack grows during the stabilizing of the resistance curve. This observation can eliminate the need for the examination of competing failure mechanisms in adhesively bonded composite joints under pure opening condition.

5.2. Strength of Hybrid Lap-Joints and Failure Modes. Table 4 shows the results for the strength of adhesive hybrid lapjoints with different bonding length: $L=15,25.4,35 \mathrm{~mm}$ and strength of the joints type I, II, and III in different loading speeds: $v=0.1,1.27,10 \mathrm{~mm} / \mathrm{min}$. As mentioned in Section 4.2 , at least three samples have been tested in each state and Table 4 data is ultimate loads average. The failure mode of hybrid lap-joint specimens is fairly complicated with the appearance of interfacial failure on the failure surface. The failure process is not easy to determine because the final failure occurred abruptly and instantaneously. The failure process could initiate in the adhesive at the free ends of the joints. The microcracks in the adhesive layer subsequently propagated along the interface between the adhesive and adherend after a short period of time. This process could occur at both free ends of the hybrid lap bonded joint. Based on Table 4, it can be seen that the ultimate strength is also increased with longer overlap. In the joint type III, when the overlap is augmented in length, the increment in ultimate strength is less significant in comparison with other joints such as type I and II.

When the length of overlap in joint type I increases from $L=15 \mathrm{~mm}$ to $L=35 \mathrm{~mm}$, the joint's strength is also increased by $175 \%$ and shows that it is heavily influenced by the longitude of its overlap. Also, in joint type II, the ultimate strength is amplified by $76 \%$ with the augmentation of overlap's length from $L=15 \mathrm{~mm}$ to $L=35 \mathrm{~mm}$. Its value for joint type III is $47 \%$. As it is explicit in the results, adding of the overlap's length with the increase of the joint's strength has the maximum effect on the joint type III, and the minimum effect on the joint type III.

Another point inferred by the results is that when the length of overlap is $L=15$ and $25 \mathrm{~mm}$ the ultimate strength of joint type II is greater than that of joint type I. And their ultimate strength is roughly equal when the overlap's length is $b=35 \mathrm{~mm}$. With respect to the joint type III, it can be said that its ultimate strength is greater than joints type I and type II in every given length of different overlaps.

This suggests that increasing the overlap length to obtain a higher failure level for a bonded joint probably is efficient only within a limited range. The specific relationship between the failure load and the length may depend on many joint-related factors. This often means that joints made with high-strength adhesives are more likely to fail prematurely in the composite adherend (fiber and matrix) before the occurrence of failure in the adhesive.

From Table 4, it is clear that the ultimate strength decreases when the loading speed increases from $0.1 \mathrm{~mm} / \mathrm{s}$ to $10 \mathrm{~mm} / \mathrm{s}$. This decline is $19.36 \%$ for the joint type $\mathrm{I}, 13.34 \%$ for the joint type II, and $17.2 \%$ for the joint type III. Here again the joint type III has the greatest ultimate strength compared to the other joints in any applied loading speed, and the joint type I is the weakest.

In the joint type I when the loading speed was $v=$ $1.27 \mathrm{~mm} / \mathrm{s}$, the cohesive failure and light-fiber failure were detected after disjointing. Figure 6(a) shows the point clearly. With the loading speed of $v=0.1 \mathrm{~mm} / \mathrm{s}$, adhesive failure and light-fiber failure were discovered. The detection of adhesive and cohesive failure can be obtained with loading speed of $v=10 \mathrm{~m} / \mathrm{s}$. All in all, the common failure of the joint type I is of adhesive and cohesive types.

In the joint type II, the light fiber failure was observed at the loading speed of $v=1.27 \mathrm{~mm} / \mathrm{s}$, and the prior failure was repeated at $v=0.1,10 \mathrm{~mm} / \mathrm{s}$. This is true for all the lengths 


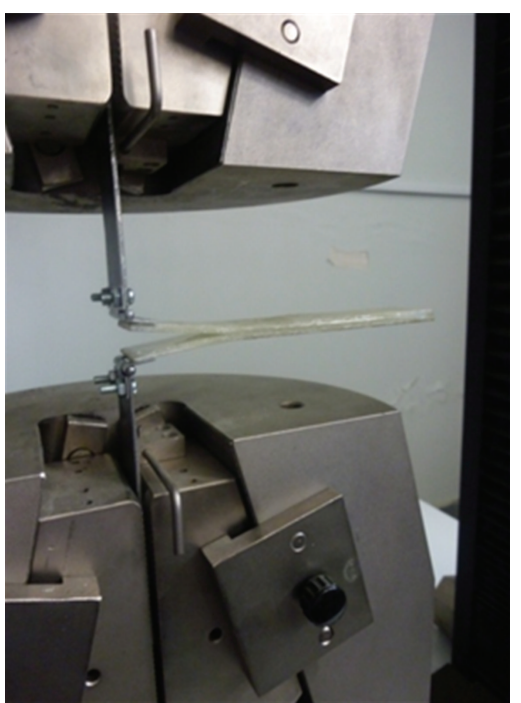

(a)

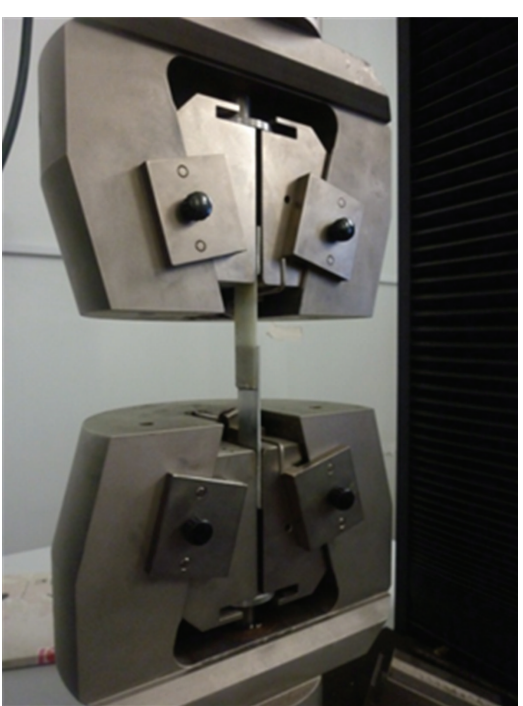

(b)

FIgURE 3: Overview of loading device and test setup of specimens. (a) DCB's, (b) adhesive hybrid lap-joint.

TABLe 2: Average critical fracture loads Pc $(N)$ for the DCB specimens with different crack lengths.

\begin{tabular}{lcccccccc}
\hline & Test & & \multicolumn{5}{c}{ Crack length (mm) } \\
& & 30 & 40 & 50 & 60 & 70 & 80 & 90 \\
\hline \multirow{3}{*}{ Critical load $(N)$} & 1 & 102 & 82.5 & 70.5 & 62 & 47.5 & 42 \\
& 2 & 90 & 91 & 69 & 58.8 & 50 & 39 & 38 \\
\hline Average & 3 & 94 & 83 & 65 & 61 & 51.5 & 42.5 & 29.5 \\
\hline
\end{tabular}

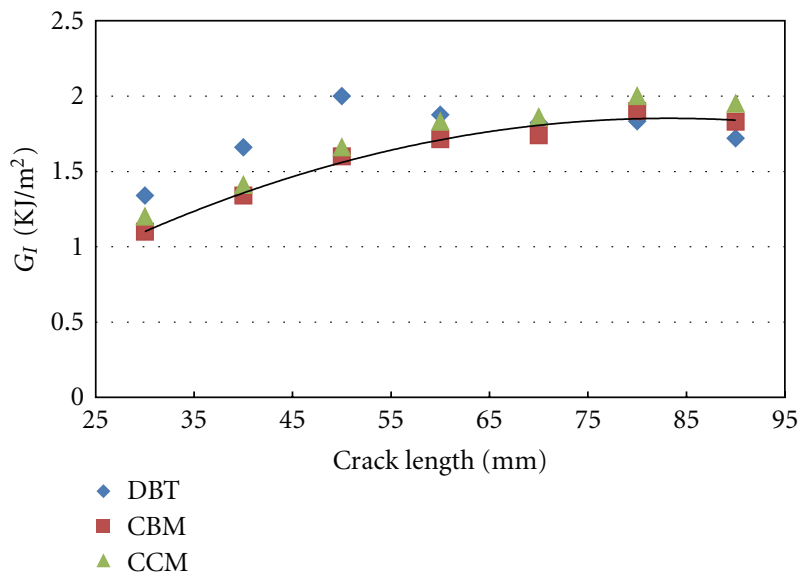

Figure 4: $R$-curves obtained by the experimental methods for the DCB tests.

of the overlaps. In one case, with the loading speed of $v=10 \mathrm{~mm} / \mathrm{s}$, the adhesive failure was identified. Generally, the light-fiber failure was the most prevailing failure mode. Figure 6(b) shows the result clearly. With regard to the failure of joint type II, it can be said that the joint of glue has been stronger than the joint of resin and fibers.

In the joint type III with the loading speed of $v=$ $1.27 \mathrm{~mm} / \mathrm{s}$, the cohesive failure was observed, and the adhesive failure occurred at the speeds of $v=0.1$ and $v=$ $10 \mathrm{~mm} / \mathrm{s}$. The adhesive and cohesive failures were prevalent in this joint. The failure in the joint type 3 is apparent in Figure 6(c). It is necessary to note that the adherend failure was not observed in none of the cases.

\section{Finite-Element (FE) Analysis}

6.1. Fracture Mechanics-Based Analysis for DCB's. The numerical simulation of the mode I fracture tests has been achieved by the finite element method using the commercial ABAQUS software [37]. The $J$-integral and stress intensity factor are widely used fracture mechanics concepts in the assessment of the fracture resistance in adhesively bonded joints $[38,39]$. In this study, the $J$-integral formulation was employed because it is useful for a coarse-meshed finiteelement analysis. The method is applicable to cracks in the isotropic and anisotropic materials. In the context of quasistatic analysis, the $J$-integral in two dimensions is defined as

$$
J=\lim _{\Gamma \rightarrow 0} \int_{\Gamma} n \cdot\left(W I-\sigma \cdot \frac{\partial u}{\partial x}\right) \cdot q d \Gamma,
$$

where $\Gamma$ is an arbitrary contour, $W$ is the elastic strain energy for elastic material, $q$ is a unit vector in the virtual crack extension direction, $n$ is the outward normal to $\Gamma, \sigma$ is the stress tensor, and $u$ is the displacement vector, as shown in 
TABLE 3: Fracture energies in the pure mode II obtained by the DBT, CBM, and CCM $\left(\mathrm{KJ} / \mathrm{m}^{2}\right)$.

\begin{tabular}{cccc}
\hline Crack length $(\mathrm{mm})$ & DBT & CBM & CCM \\
\hline 30 & 1.34 & 1.1 & 1.2 \\
40 & 1.66 & 1.34 & 1.41 \\
50 & 2 & 1.66 & 1.66 \\
60 & 1.876 & 1.714 & 1.83 \\
70 & 1.86 & 1.74 & 1.86 \\
80 & 1.9 & 1.9 & 2 \\
90 & 1.72 & 1.83 & 1.95 \\
\hline Average $G_{I}$ & 1.765 & 1.612 & 1.701 \\
\hline
\end{tabular}

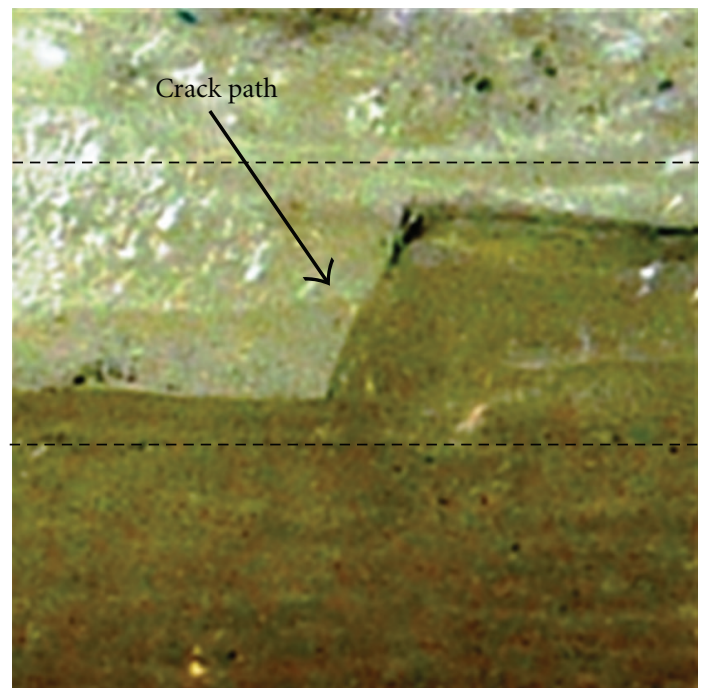

(a)

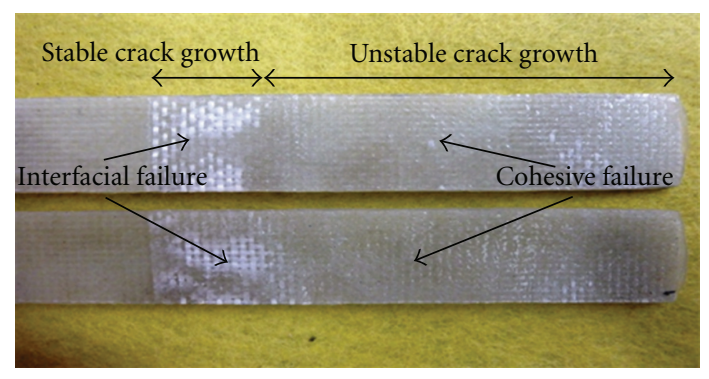

(b)

Figure 5: (a) A typical crack path under the opening load case, (b) failure surfaces of the DCB specimen after debonding.

Figure 7(a). Several contours integral evaluations are possible at each location along a crack. In a finite-element model, each evaluation could be thought of as the virtual motion of a block of material surrounding the crack tip (in two dimensions) or surrounding each node along the crack line (in three dimensions). Each contour provides an evaluation of the contour integral. The number of possible evaluations is the number of such rings of elements. Figure 7(b) shows contours surrounding the crack tip. In the linear elastic fracture mechanics, the $J$-integral is equal to total energy release rate, $J=G_{T}=G_{I}+G_{I I}+G_{I I I}$, where $G_{I}, G_{I I}$, and
$G_{I I I}$ are the energy release rates associated with the mode-I, mode-II, and mode-III loading conditions. In the DCB test, just the mode-I exists and it can be expressed as $J=G_{T}=G_{I}$.

Figure 7(c) shows an example of the mesh pattern around the crack tip using the ABAQUS software. The entire specimen was modeled using eight node collapsed quadrilateral element and the mesh was refined around the crack tip, so that the smallest element size found in the crack-tip elements was approximately $0.2 \mathrm{~mm}$. A linear elastic finite-element analysis was performed under a plain strain condition using $1 / \sqrt{r}$ stress field singularity. To obtain a $1 / \sqrt{r}$ singularity term of the crack-tip stress field, the elements around the crack tip were focused on the crack-tip and the mid-side nodes were moved to a quarter point of each element side. The loads corresponding to the crack initiation in the DCB tests were used to the finite-element solution. As a part of study, the variation of $G_{I C}$ versus different crack length has been investigated. Figure 8 shows the $R$-curve computed by $J$-integral method. The mean value of critical fracture energy by FE results is $G_{J \text {-integral }}=1.765\left(\mathrm{Kj} / \mathrm{m}^{2}\right)$. According to numerical prediction, $G_{I C}$ are obtained with good comparability with the corresponding experimental results (Section 5.1) for all crack lengths. It can be seen that $G_{I C}$ obtained from the numerical analyses increase with the growth of crack length, while the increase of crack length leads to a stable fracture resistance in the DCB tests. The results of experiment tests (Section 5.1) and numerical analysis showed good agreement demonstrating the effectiveness of the proposed experiment and numerical methods.

6.2. Stress Distribution of Adhesive Layer in Hybrid LapJoints. Numerical analysis of the adhesive joints for singlelap adhesive joint involved determining the mean value of the destructive load as recorded in the experimental tests. The adhesive used was an elastic-traction material, which recorded failure of cohesive elements. ABAQUS/Standard software was used as the numerical tool for calculations in order to conduct FEM analyses. The number of elements of tested materials was on average 3,000-3,500 elements for each sample, and about 500-600 elements for the adhesive layer. The number of elements for the entire mesh and for the adhesive layer depended on the type of adhesive joints. The adhesive joint was modeled with cohesive type elements COH3D8 characteristic of the specific properties demonstrated by such materials as adhesives. These elements are 
TABLE 4: Adhesive hybrid lap-joint strength in tension for three type of joints $(\mathrm{N})$.

\begin{tabular}{|c|c|c|c|c|c|c|}
\hline \multirow{2}{*}{ Joint type } & \multicolumn{3}{|c|}{ Overlap length (mm) } & \multicolumn{3}{|c|}{ Loading speed (mm/min) } \\
\hline & 15 & 25.4 & 35 & .1 & 1.27 & 10 \\
\hline I & 2420 & 4462 & 6675 & 5320 & 4462 & 4290 \\
\hline II & 3650 & 5160 & 6460 & 5383 & 5160 & 4665 \\
\hline III & 5025 & 5800 & 7405 & 6098 & 5765 & 5050 \\
\hline
\end{tabular}

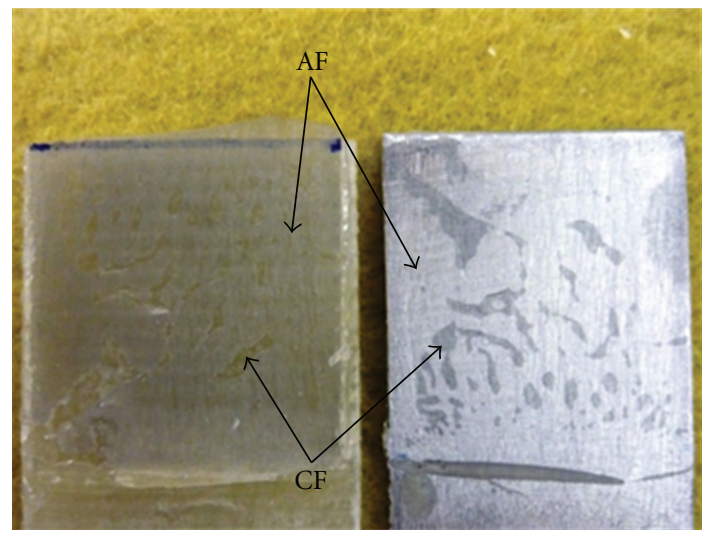

(a)

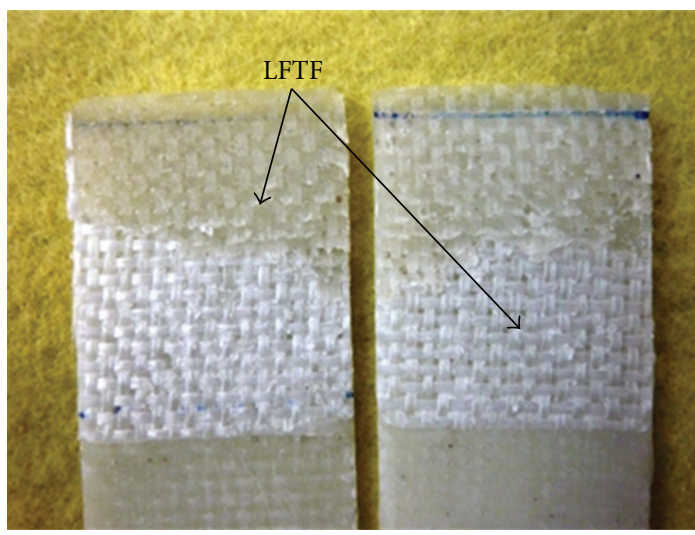

(b)

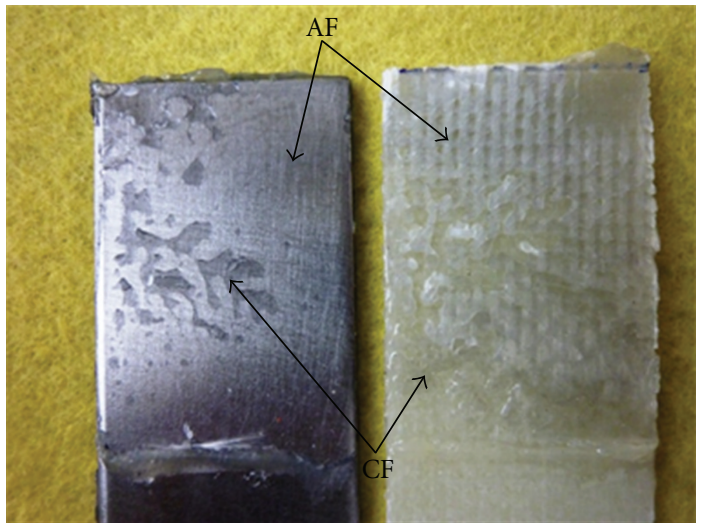

(c)

FIgURE 6: Failure modes for joints in the tensile test, (a) joint type I, (b) joint type II, (c) joint type III.

but a few used in ABAQUS and as such are subject to threedimensional analyses [37]. The model presents a situation in which connecting cohesive elements to other components (materials) was realized by applying surface-base tie constraints as there was no match between the meshes of two neighboring parts. Owing to these elements, it was possible to model the adhesive joint failure in the analyzed adhesive joints. The literature $[3,12,13,29,36]$ provide increasing amounts of information on modeling adhesive joints using this type of element. Figure 9 shows detailed view of FEM modeled. The essential constitutive law describing cohesive elements is failure criterion called traction-separation (tearing force-maximum separation value) which allows taking into consideration both normal interactions (tearing) and the effects of failure caused by tangential interaction. Figure 10 shows the normalized von-misses stress distribution of the cohesive layer with the applied failure load.
As can be seen from the figure, the stress at the free edges of the joint (ends of the lap zone) shows the maximum value and the minimum value of stress occurred at the middle of adhesive layer.

This, in turn, results in possible failure of bonding in this region (free edges of the joint). In the experiments, it was found that the initiation failure accrues at the free edges. The FE showed that the maximum stress concentration at the free edges and confirmed the failure initiation at this zone. Recent issue was observed in all types of connections type I, II, and III.

\section{Conclusions}

In this study, the mode-I fracture behavior and strength of adhesively bonded bimaterial joints was investigated under tension condition based on the experimental and numerical 


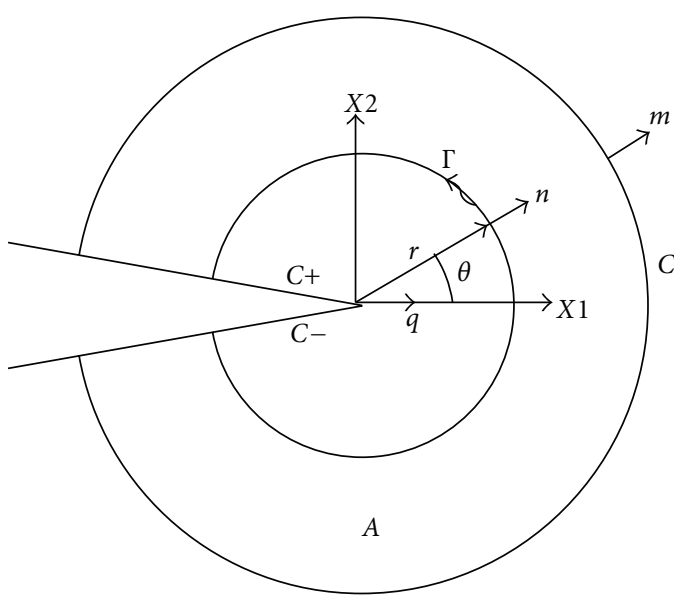

(a)
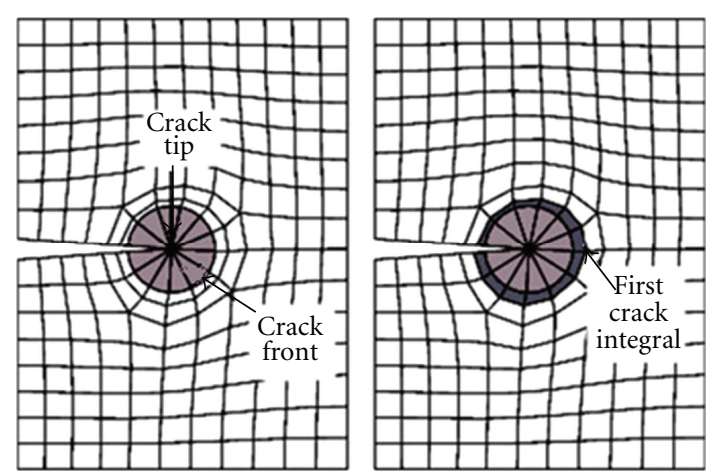

(b)
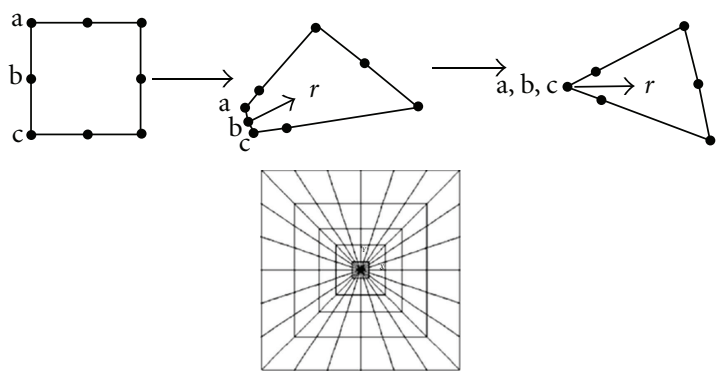

(c)

Figure 7: (a) Contour for evaluation of the J-integral. (b) Contour integral around the crack tip. (c) Finite element mesh pattern of around the crack-tip of DCB [36].

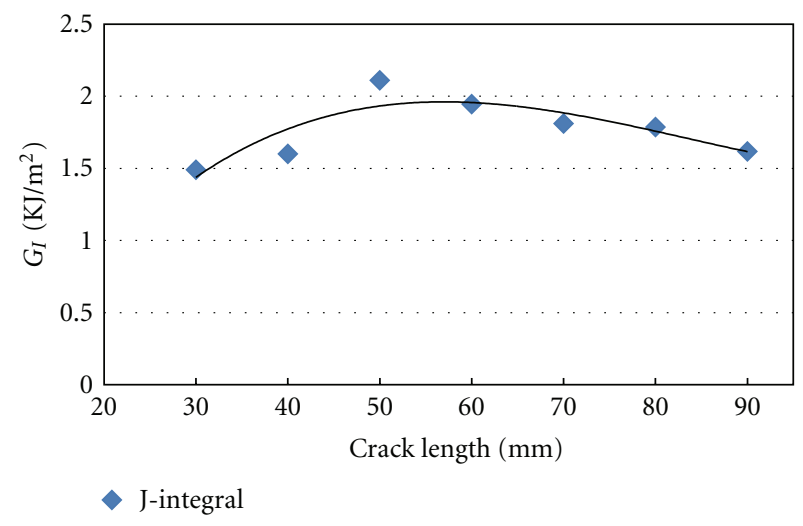

FIgURE 8: R-curves obtained by $J$-integral method for DCB tests.

analyses. The results obtained from the DCB tests and detailed examinations of the failure surfaces and numerical methods indicate the following.

(1) In all of the crack lengths, the crack growth is stable without any instability in the cracks growth.

(2) Under this loading condition, the embedded crack initiated upwards into the adhesive layer with kinking angle of $60^{\circ}$.
(3) The given procedures in the Section 2 for strain energy release rate calculation produced nearly equal quantities and it can be said that these procedures are suitable for the estimation of fracture energy in the mode-I loading.

(4) By comparing the numerical outcomes through the $J$-integral method and the resultant quantities generated by DBT, CBM, and CCM, it is proved that the suggested numerical procedures are acceptable for the measurement of fracture energy in these adhesive joints.

The main conclusions of this work in the case of adhesive hybrid lap-joints are as follows.

(1) Based on the test results presented in Table 4, it could be said that the greatest strength was obtained for the adhesive joints type III, and the lowest strength is for type I.

(2) In all of the joints, increasing the overlap's length adds to the ultimate strength. Also, the ultimate strength decreases with the escalation of the loading speed.

(3) $\mathrm{AD}$ and $\mathrm{CF}$ are the common failures for the joint type I, LFTF for joint type II, and AF and CF for joint type III.

(4) Numerical statistics depicted that stresses are at their maximum intensity in the free edges of the joint; 


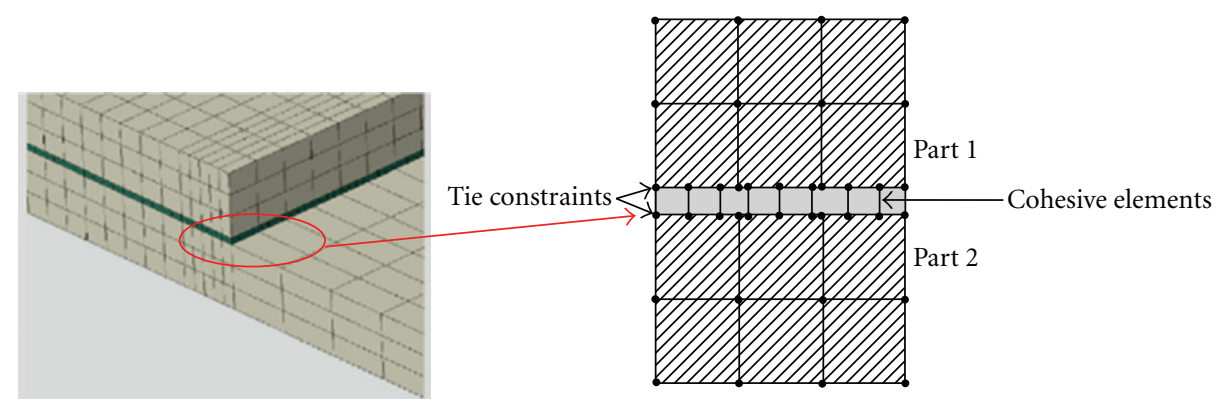

FIgURE 9: Detailed view of FEM modeled [37].

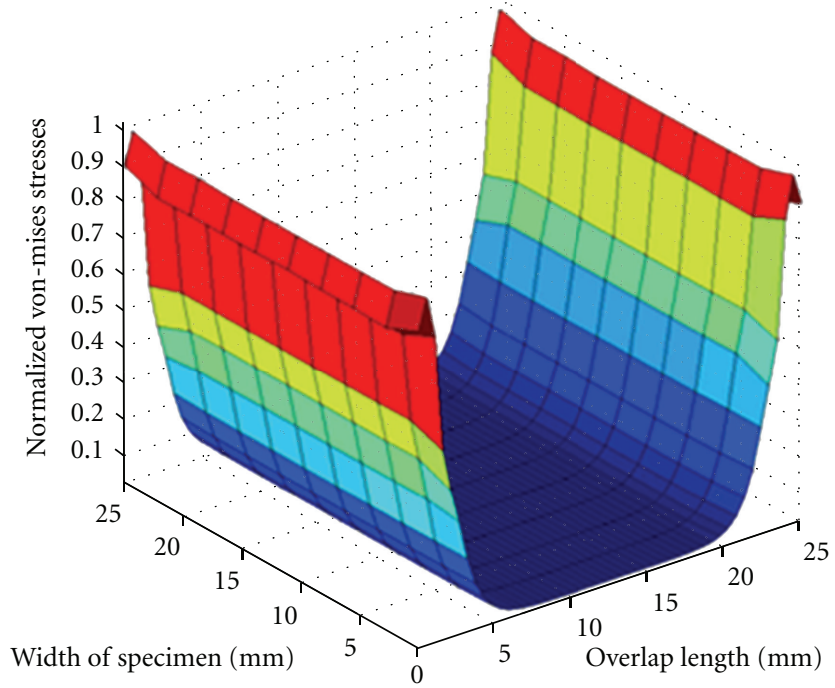

Figure 10: Distribution of von-misses stress in adhesive layer.

and this was observed in the practical experiment which confirmed the fact that the failures had been happened in the free edges of the joint.

The research conducted for this paper assumed that the adhesive bond line was homogenous and linear elastic. To accurately understand the durability of adhesively bonded joints, it is necessary to have knowledge of the effect of high temperatures and/or high humidity levels on the entire adherend-adhesive system. In order to understand deeply of the fracture behaviour of adhesively bonded joints and to fully achieve the benefits of adhesive bonding, the determination of environmental effects such as combinations of moisture and temperature both in the cohesive and interfacial regions is needed. In many cases, environmental attack causes adhesive degradation (interface or interphase regions); however, adhesive properties may also be affected (cohesive degradation). The durability of adhesively bonded joints presented by several researchers suggests that heat and moisture are detrimental to bond performance. For example, moisture absorption and elevated temperatures by increasing plasticization may affect the applicability of linear elastic fracture mechanics criterion and increase the toughness of a bond line. Some degree of future work can focus on investigating alternate approach using elastic-plastic fracture mechanics in the adhesively bonded joints. In order to extend understanding of the fracture behavior and more accurately determine a failure criterion for adhesively bonded composite joints, additional tests should be conducted with other specimen geometries. These could be accomplished using a number of methods including, ENF (End Notched Flexure) for mode-II and MMB (Mixed Mode Bending) for mixedmode fracture tests. Some more analytical work may also be required to consider the fracture of adhesively bonded joints. Existing methods and codes may be modified or new ones developed to predict strain energy release rate values and failures of adhesively bonded joints. Finally, while this work has made contributions to the knowledge of adhesively bonded joints, much more research needs to be accomplished; particularly the effect of environmental exposure (temperature and humidity) on the performance of adhesively bonded joints must also not be ignored.

\section{Acknowledgments}

The author would like to thank the Institute of Standard and Industrial Researches (Arak, Iran) for kindly provided access to their facilities. He also would like to thank the collaboration of Mr. Yousefi and his valuable time, advice and guidance throughout this work.

\section{References}

[1] I. A. Ashcroft, D. J. Hughes, and S. J. Shaw, "Mode I fracture of epoxy bonded composite joints: 1. Quasi-static loading," International Journal of Adhesion and Adhesives, vol. 21, no. 2, pp. 87-89, 2001.

[2] B. R. K. Blackman, A. J. Kinloch, M. Paraschi, and W. S. Teo, "Measuring the mode I adhesive fracture energy, GIC, of structural adhesive joints: the results of an international round-robin," International Journal of Adhesion and Adhesives, vol. 23, no. 4, pp. 293-305, 2003.

[3] M. F. S. F. D. Moura, R. D. S. G. Campilho, and J. P. M. Goncalves, "Crack equivalent concept applied to the fracture characterization of bonded joints under pure mode I loading," Composites Science and Technology, vol. 68, no. 10-11, pp. 2224-2230, 2008.

[4] T. Andersson and U. Stigh, "The stress-elongation relation for an adhesive layer loaded in peel using equilibrium of energetic forces," International Journal of Solids and Structures, vol. 41, no. 2, pp. 413-434, 2004. 
[5] J. A. Nairn, "Energy release rate analysis for adhesive and laminate double cantilever beam specimens emphasizing the effect of residual stresses," International Journal of Adhesion and Adhesives, vol. 20, no. 1, pp. 59-70, 2000.

[6] B. R. K. Blackman, A. J. Kinloch, M. Paraschi, and W. S. Teo, "The determination of the mode II adhesive fracture resistance, GIIC, of structural adhesive joints: an effective crack length approach," Engineering Fracture Mechanics, vol. 72, no. 6, pp. 877-897, 2005.

[7] M. F. S. F. D. Moura, R. D. S. G. Campilho, and J. P. M. Goncalves, "Pure mode II fracture characterization of composite bonded joints," International Journal of Solids and Structures, vol. 46, no. 6, pp. 1589-1595, 2009.

[8] K. Leffler, K. S. Alfredsson, and U. Stigh, "Shear behaviour of adhesive layers," International Journal of Solids and Structures, vol. 44, no. 2, pp. 530-545, 2007.

[9] T. A. Hafiz, M. M. A. Wahab, A. D. Crocombe, and P. A. Smith, "Mixed-mode fracture of adhesively bonded metallic joints under quasi-static loading," Engineering Fracture Mechanics, vol. 77, no. 17, pp. 3434-3445, 2010.

[10] A. Ameli, M. Papini, J. A. Schroeder, and J. K. Spelt, "Fracture R-curve characterization of toughened epoxy adhesives," Engineering Fracture Mechanics, vol. 77, no. 3, pp. 521-534, 2010.

[11] N. Choupani, "Mixed-mode cohesive fracture of adhesive joints: experimental and numerical studies," Engineering Fracture Mechanics, vol. 75, no. 15, pp. 4363-4382, 2008.

[12] B. R. K. Blackman, H. Hadavinia, A. J. Kinloch, and J. G. Williams, "The use of a cohesive zone model to study the fracture of fibre composites and adhesively-bonded joints," International Journal of Fracture, vol. 119, no. 1, pp. 25-46, 2003.

[13] S. Li, M. D. Thouless, A. M. Waas, J. A. Schroeder, and P. D. Zavattieri, "Use of mode-I cohesive-zone models to describe the fracture of an adhesively-bonded polymer-matrix composite," Composites Science and Technology, vol. 65, no. 2, pp. 281-293, 2005.

[14] G. Alfano and M. A. Crisfield, "Finite element interface models for the delamination analysis of laminated composites: mechanical and computational issues," International Journal for Numerical Methods in Engineering, vol. 50, no. 7, pp. 17011736, 2001.

[15] D. Xie and S. B. Biggers Jr., "Progressive crack growth analysis using interface element based on the virtual crack closure technique," Finite Elements in Analysis and Design, vol. 42, no. 11, pp. 977-984, 2006.

[16] R. D. Adams, J. Comyn, and W. C. Wake, Structural Adhesive Joints in Engineering, Chapman \& Hall, London, UK, 2nd edition, 1997.

[17] A. J. Kinloch, Adhesion and Adhesives. Science and Technology, Chapman \& Hall, London, UK, 1987.

[18] A. Baldan, "Adhesively-bonded joints and repairs in metallic alloys, polymers and composite materials: adhesives, adhesion theories and surface pretreatment," Journal of Materials Science, vol. 39, no. 1, pp. 1-49, 2004.

[19] C. Borsellino, G. D. Bella, and V. F. Ruisi, "Adhesive joining of aluminium AA6082: the effects of resin and surface treatment," International Journal of Adhesion and Adhesives, vol. 29, no. 1, pp. 36-44, 2009.

[20] J. H. Kweon, J. W. Jung, T. H. Kim, J. H. Choi, and D. H. Kim, "Failure of carbon composite-to-aluminum joints with combined mechanical fastening and adhesive bonding," Composite Structures, vol. 75, no. 1-4, pp. 192-198, 2006.

[21] A. M. G. Pinto, R. D. S. G. Campilho, I. R. Mendes, S. M. Aires, and A. P. M. Baptista, "Effect of hole drilling at the overlap on the strength of single-lap joints," International Journal of Adhesion and Adhesives, vol. 31, no. 5, pp. 380-387, 2011.

[22] T. Sawa, J. Liu, K. Nakano, and J. Tanaka, "A two-dimensional stress analysis of single-lap adhesive joints of dissimilar adherends subjected to tensile loads," Journal of Adhesion Science and Technology, vol. 14, no. 1, pp. 43-66, 2000.

[23] C. Yang, H. Huang, J. S. Tomblin, and W. Sun, "Elastic-plastic model of adhesive-bonded single-lap composite joints," Journal of Composite Materials, vol. 38, no. 4, pp. 293-309, 2004.

[24] L. Tong, "Strength of adhesively bonded single-lap and lapshear joints," International Journal of Solids and Structures, vol. 35, no. 20, pp. 2601-2616, 1998.

[25] X. S. Xiao, P. H. Foss, and J. A. Schroeder, "Stiffness prediction of the double lap shear joint. Part1: analytical solution," International Journal of Adhesion and Adhesives, vol. 24, no. 3, pp. 229-237, 2004.

[26] M. Y. Tsai, D. W. Oplinger, and J. Morton, "Improved theoretical solutions for adhesive lap joints," International Journal of Solids and Structures, vol. 35, no. 12, pp. 1163-1185, 1998.

[27] S. C. Her, "Stress analysis of adhesively-bonded lap joints," Composite Structures, vol. 47, no. 1-4, pp. 673-678, 1999.

[28] Q. Luo and L. Tong, "Linear and higher order displacement theories for adhesively bonded lap joints," International Journal of Solids and Structures, vol. 41, no. 22-23, pp. 6351-6381, 2004.

[29] S. M. R. Khalili, A. Shokuhfar, S. D. Hoseini, M. Bidkhori, S. Khalili, and R. K. Mittal, "Experimental study of the influence of adhesive reinforcement in lap joints for composite structures subjected to mechanical loads," International Journal of Adhesion and Adhesives, vol. 28, no. 8, pp. 436-444, 2008.

[30] L. Tong, A. Sheppard, and D. Kelly, "The effect of adherend alignment on the behaviour of adhesively bonded double lap joints," International Journal of Adhesion and Adhesives, vol. 16, no. 4, pp. 241-247, 1996.

[31] T. L. Anderson, Fracture Mechanic: Fundamental and Applications, CRC press, 2nd edition, 1995.

[32] ASTM Standard D 5573-99, "Standard practice for classifying failure modes in fiber-reinforced-plastic (FRP) joints," in Annual Book of ASTM Standards, vol. 15.03, ASTM, Conshohocken, Pa, USA, 2007.

[33] D. Gay, S. V. Hoa, and S. W. Tsai, Composite materials: Design and Applications, CRC press, 2003.

[34] 2011, http://www.mokarrar.com.

[35] ASTM Standard D-5528, “Test method for mode I interlaminar fracture toughness of unidirectional fiber-reinforced polymer matrix composites," in Annual Book of ASTM Standards, vol. 15.03, ASTM, Conshohocken, Pa, USA, 2004.

[36] D. Xie, A. M. Waas, K. W. Shahwan, J. A. Schroeder, and R. G. Boeman, "Fracture criterion for kinking cracks in a trimaterial adhesively bonded joint under mixed mode loading," Engineering Fracture Mechanics, vol. 72, no. 16, pp. 2487-2504, 2005.

[37] ABAQUS User's Manual Version 6.2.4, Habbit, Karlsson and Sorensen, Pawtucket, RI, USA, 2004.

[38] N. Choupani, "Interfacial mixed-mode fracture characterization of adhesively bonded joints," International Journal of Adhesion and Adhesives, vol. 28, no. 6, pp. 267-282, 2008.

[39] Z. Chen, R. D. Adams, and L. F. M. da Silva, "The use of the J-integral vector to analyse adhesive bonds with and without a crack," International Journal of Adhesion and Adhesives, vol. 31, no. 1, pp. 48-55, 2011. 

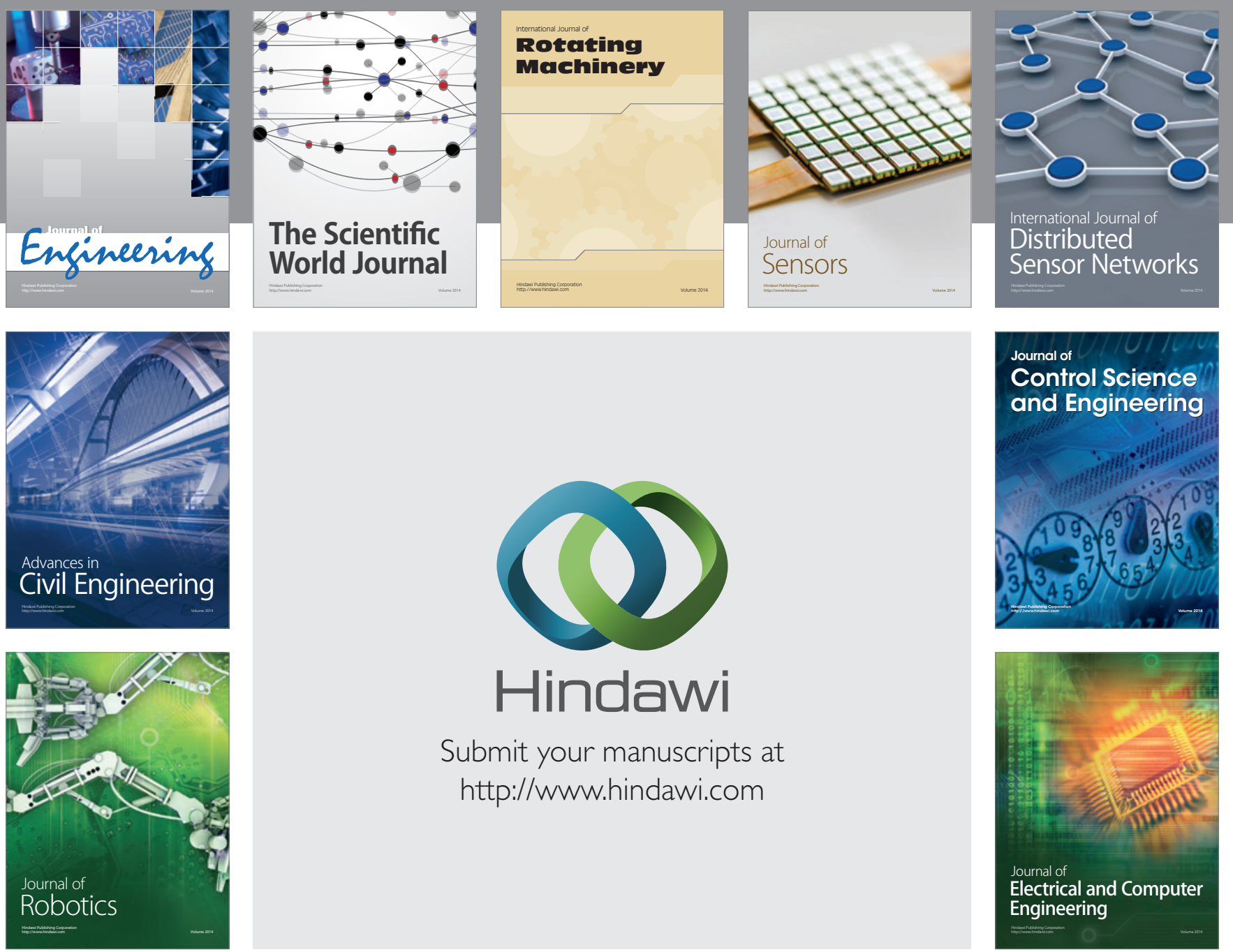

Submit your manuscripts at

http://www.hindawi.com
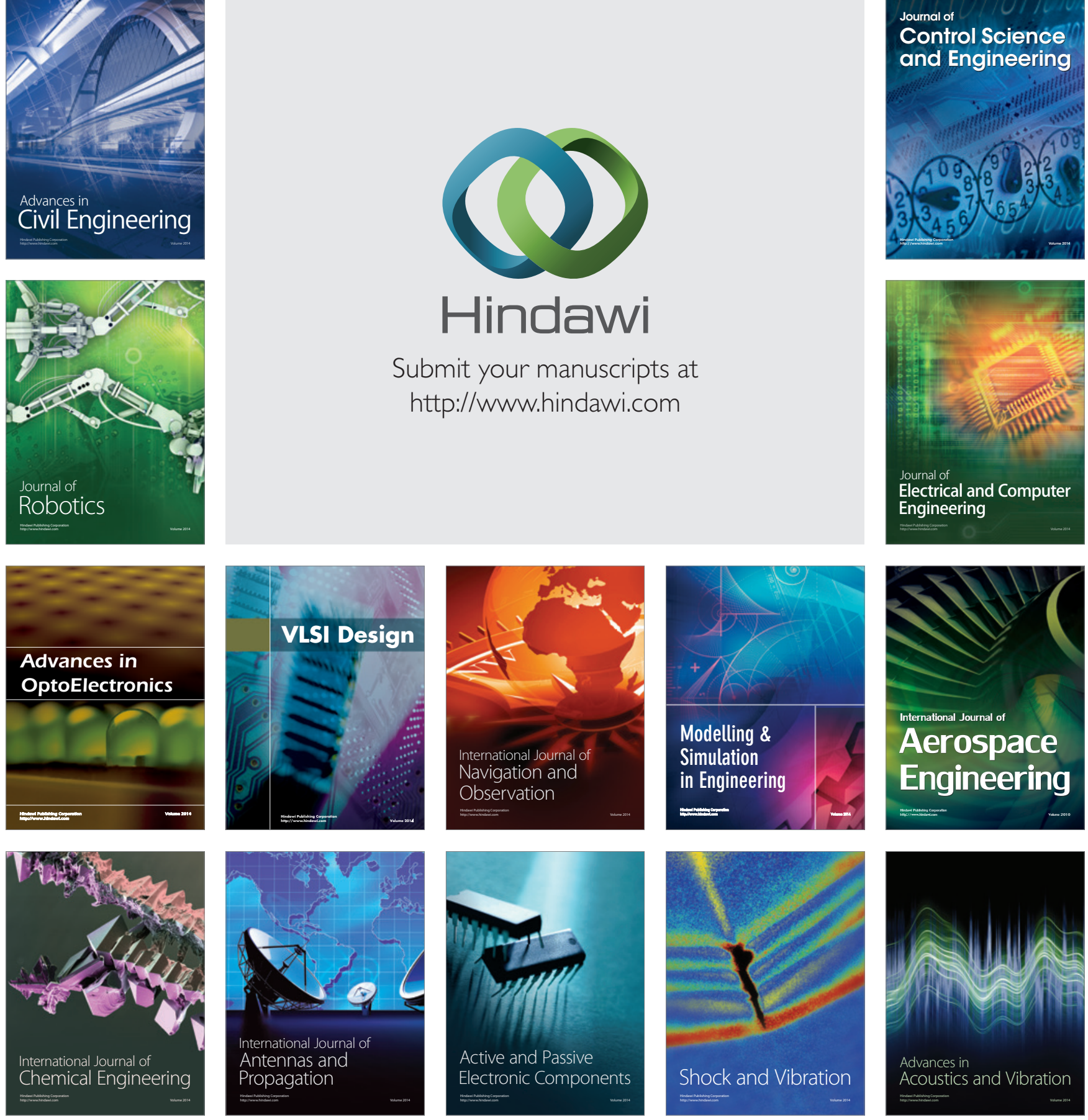